\title{
Structure and activities of adult congenital heart disease programmes in Europe
}

\author{
Philip Moons ${ }^{1,2 *}$, Folkert J. Meijboom ${ }^{3}$, Helmut Baumgartner ${ }^{4}$, Pedro T. Trindade ${ }^{5}$, \\ Els Huyghe ${ }^{1}$, and Harald Kaemmerer ${ }^{6}$ on behalf of the ESC Working Group on \\ Grown-up Congenital Heart Disease
}

\begin{abstract}
${ }^{1}$ Centre for Health Services and Nursing Research, Katholieke Universiteit Leuven, Kapucijnenvoer 35, PO Box 7001, B-3000 Leuven, Belgium; ${ }^{2}$ Division of Congenital and Structural Cardiology, University Hospitals of Leuven, Leuven, Belgium; ${ }^{3}$ Department of Cardiology, University Medical Centre Utrecht, Utrecht, The Netherlands; ${ }^{4}$ Kardiologischen Zentrums für Erwachsene mit angeborenen (EMAH) und erworbenen Herzfehlern, University Hospital Muenster, Muenster, Germany; ${ }^{5}$ Cardiology, University Hospital, Zurich, Switzerland; and ${ }^{6}$ Klinik fur Kinderkardiologie und angeborene Herzfehler, Deutsches Herzzentrum Munchen, Munich, Germany
\end{abstract}

Received 30 June 2009; revised 19 September 2009; accepted 18 October 2009; online publish-ahead-of-print 22 December 2009

\section{Introduction}

The tremendous improvement in life expectancy of patients born with a heart defect has prompted health-care institutions and individual health-care providers to develop facilities that specifically care for these patients as they grow older. The importance of specific adult congenital heart disease (ACHD) programmes is corroborated by European and North American guidelines for the management of ACHD patients. ${ }^{1,2}$ Hence, an increasing number of structured and unstructured programmes for adults with congenital heart disease have been established worldwide. ${ }^{3,4}$ Several reports, however, indicate that the number of available cardiologists and post-graduate medical fellows who are receiving specialized training in congenital heart disease is not meeting the estimated workforce requirements to care for the vast amount of affected patients. ${ }^{5-7}$

International recommendations state that one ACHD specialist centre is needed for every 5-10 million inhabitants. ${ }^{1,8}$ This means that for the European population of 730 million (http://esa.un.org/unpp/), 70-140 centres would be needed. A recent North American report, however, suggested that one centre per 2 million inhabitants can more realistically meet the needs of ACHD patients. ${ }^{9}$ For Europe, this translates to 365 ACHD centres.

In addition to the number of ACHD programmes, the structure of such programmes is also important. ${ }^{3,10}$ Therefore, the European Society of Cardiology (ESC) Working Group on Grown-up Congenital Heart Disease surveyed European ACHD programmes to assess their staffing, clinical activities, available equipment, training, and supportive services. This article reports on the results of this survey.

\section{Methods}

\section{Participating centres}

We conducted a descriptive, cross-sectional survey of specialized ACHD centres in Europe. Fifty-six potential participating centres were identified through the ESC Working Group on Grown-up Congenital Heart Disease. We invited these centres to participate in our survey by sending an email to the respective head of the ACHD programme. These centres were asked to add ACHD programmes that were missing in the initial list. Fourteen programmes were added, resulting in a study population of 70 centres.

Overall, 53 centres voluntarily participated in our survey, yielding a response rate of $76 \%$. For the analyses, only specialist $A C H D$ programmes were included. To determine specialist centres, we relied on the definition of the Euro Heart Survey on Adult Congenital Heart Disease. ${ }^{10}$ Specialist centres are those complying with the following criteria: (i) must offer paediatric cardiology or congenital cardiac surgery; (ii) must have on-staff at least one cardiologist dedicated to ACHD; and (iii) must have more than 200 ACHD patients under regular follow-up care. ${ }^{10}$ Three of the 53 centres $(5.7 \%)$ did not fulfil the requirements for specialist centres and were therefore debarred from the analyses. The 50 specialist centres originated from 18 countries (Figure 1). The UK, Germany, and Sweden were highly represented. The first programme was established in 1964. This was a combined paediatric cardiology/heart surgery/ACHD programme. The first dedicated ACHD programmes were founded in the mid-1970s. An exponential growth in programmes was observed in the 1990s (Figure 2). Forty-seven programmes (94\%) were located in a university hospital.

\section{Measurements}

We devised a specific questionnaire for this survey. This questionnaire, which comprised 53 items, was based on a survey form that was used

\footnotetext{
* Corresponding author. Tel: +3216 336984, Fax: + 3216 336970, Email: philip.moons@med.kuleuven.be

The opinions expressed in this article are not necessarily those of the Editors of the European Heart Journal or of the European Society of Cardiology.

Published on behalf of the European Society of Cardiology. All rights reserved. (C) The Author 2009. For permissions please email: journals.permissions@oxfordjournals.org.
} 


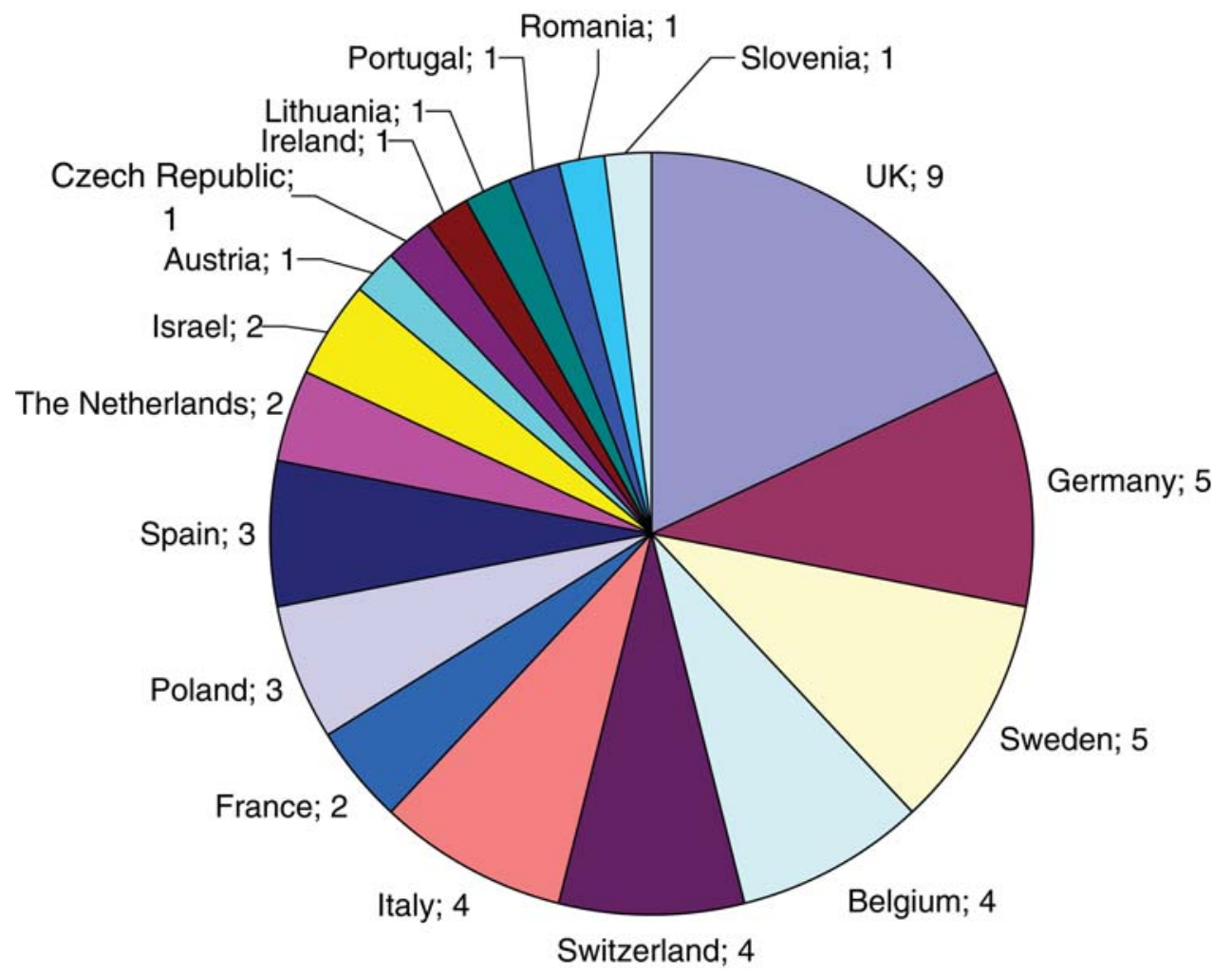

Figure I Geographic distribution of the 50 adult congenital heart disease programmes.
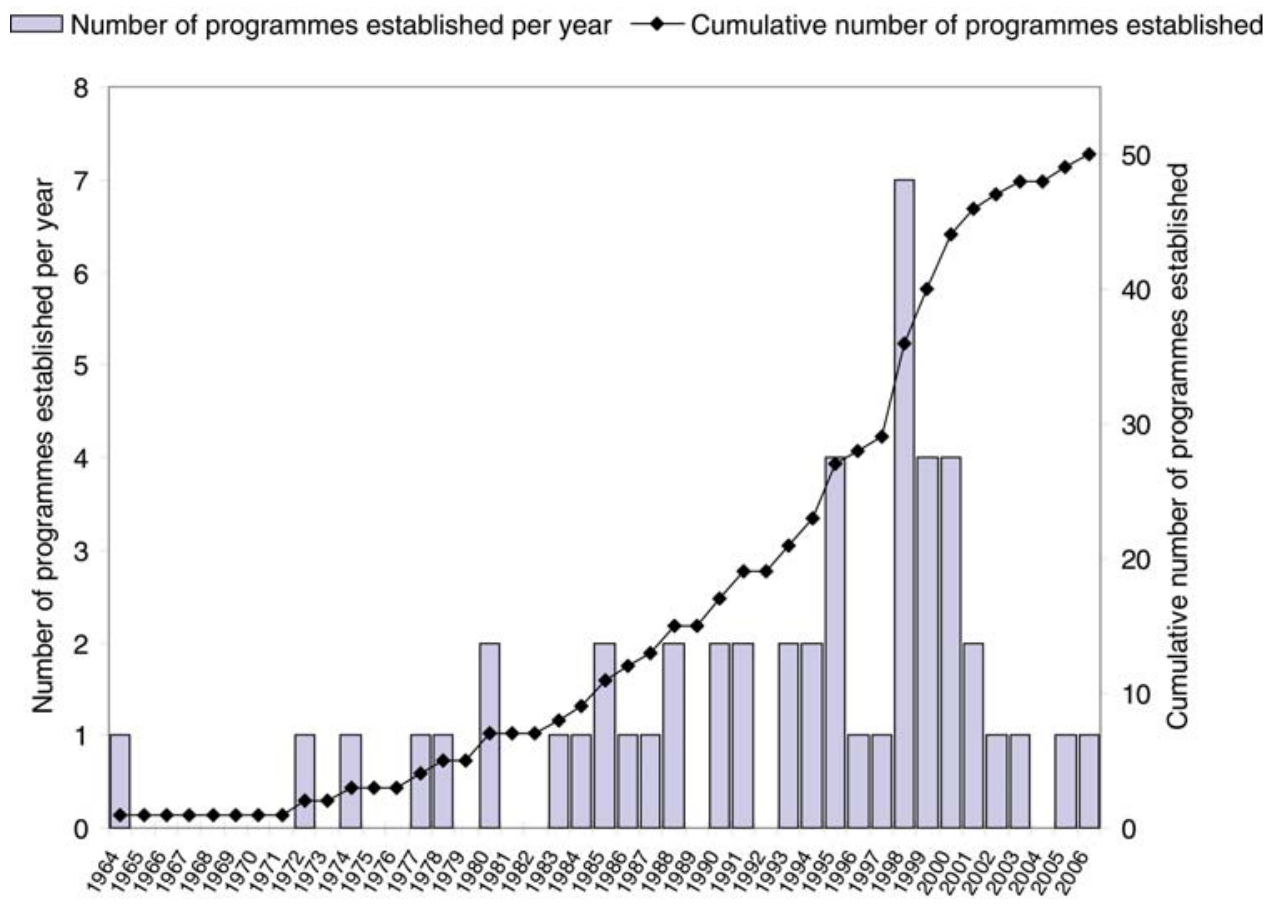

Figure 2 Number of adult congenital heart disease programmes established annually. 
previously by the ESC Working Group on Grown-up Congenital Heart Disease. The requested information referred to the 2006 data. Completing the questionnaire required $\sim 15 \mathrm{~min}$. Confidentiality of information on the patient population, clinical activity, and equipment was guaranteed. Since the survey pertained to ACHD programmes and no patients were involved, our study was considered to be a service evaluation. Therefore, ethical review by an institutional review board was not required.

\section{Data analysis}

Data were analysed with SPSS statistical software version 12.0 (SPSS Inc., Chicago, IL, USA). Nominal-level data were expressed as percentages. Medians and quartiles $(\mathrm{Q} 1-\mathrm{Q} 3)$ were calculated for continuous, non-normally distributed variables. Spearman's $\rho$ was calculated as correlation coefficients.

\section{Results}

\section{Staff}

In $94 \%$ of the participating centres, ACHD cardiologists were available (Table 1). Eighty-six per cent of the centres had on-staff one or more paediatric cardiologists; $86 \%$ had congenital heart surgeons and $68 \%$ had specialized ACHD nurses. A median of two ACHD cardiologists, paediatric cardiologists, and congenital heart surgeons were employed by the centres. A median of one nurse specialist was employed (Table 1).

\section{Clinical activity}

A median of 1500 patients was in active follow-up across centres (Table 2). Overall, the participating centres had $\sim 100000$ patients in active follow-up. The ACHD programmes had a median of 4 outpatient clinic days per week, during which they cared for a median of 26 patients per week. The median overall number of outpatient visits and hospital admissions was 800 and 130 per year, respectively. The median number of diagnostic catheter procedures, interventional catheter procedures, and cardiosurgical operations was equally distributed. The peri-operative mortality of $\mathrm{ACHD}$ patients was estimated to be about $1 \%$. The centres' number of years in operation was positively correlated with the overall number of outpatient visits per year $(\rho=0.367, P=0.013)$.

Table I Staff of the $\mathbf{5 0}$ adult congenital heart disease programmes

\begin{tabular}{|c|c|c|}
\hline & $\begin{array}{l}\text { Number of } \\
\text { centres that } \\
\text { employ this } \\
\text { professional, } n(\%)\end{array}$ & $\begin{array}{l}\text { Number of } \\
\text { professionals in the } \\
\text { centre, median } \\
\text { (Q1-Q3) }\end{array}$ \\
\hline ACHD cardiologists & $47(94)$ & $2(2-3)$ \\
\hline Paediatric cardiologists & $43(86)$ & $2(1-4)$ \\
\hline $\begin{array}{l}\text { Cardiovascular } \\
\text { surgeons dedicated } \\
\text { to ACHD surgery }\end{array}$ & $43(86)$ & $2(1-2.75)$ \\
\hline Nurse specialists & $34(68)$ & $1(0-2)$ \\
\hline
\end{tabular}

Table 2 Clinical activity in the $\mathbf{5 0}$ adult congenital heart disease programmes

\begin{tabular}{|c|c|}
\hline & $\begin{array}{l}\text { Median } \\
\text { (Q1-Q3) }\end{array}$ \\
\hline Number of ACHD patients in active follow-up & $1500(800-2900)$ \\
\hline Number of outpatient clinic days per week & $4(2-5)$ \\
\hline Number of patients per week & $26(15-45)$ \\
\hline $\begin{array}{l}\text { Number of hours per week (on average) spent } \\
\text { on ACHD care by ACHD cardiologists }\end{array}$ & $30(16.5-47.5)$ \\
\hline $\begin{array}{l}\text { Number of ACHD patients seen at the } \\
\text { outpatient clinic per year }\end{array}$ & $800(480-1314)$ \\
\hline Number of hospital admissions per year & $130(67.5-245)$ \\
\hline $\begin{array}{l}\text { Number of diagnostic catheter procedures per } \\
\text { year }\end{array}$ & $31(15-72.5)$ \\
\hline $\begin{array}{l}\text { Number of interventional catheter procedures } \\
\text { per year }\end{array}$ & $45(19-84)$ \\
\hline Number of cardiosurgical procedures per year & $35(14-55)$ \\
\hline Percentage of peri-operative mortality & $1(0-2.5)$ \\
\hline
\end{tabular}

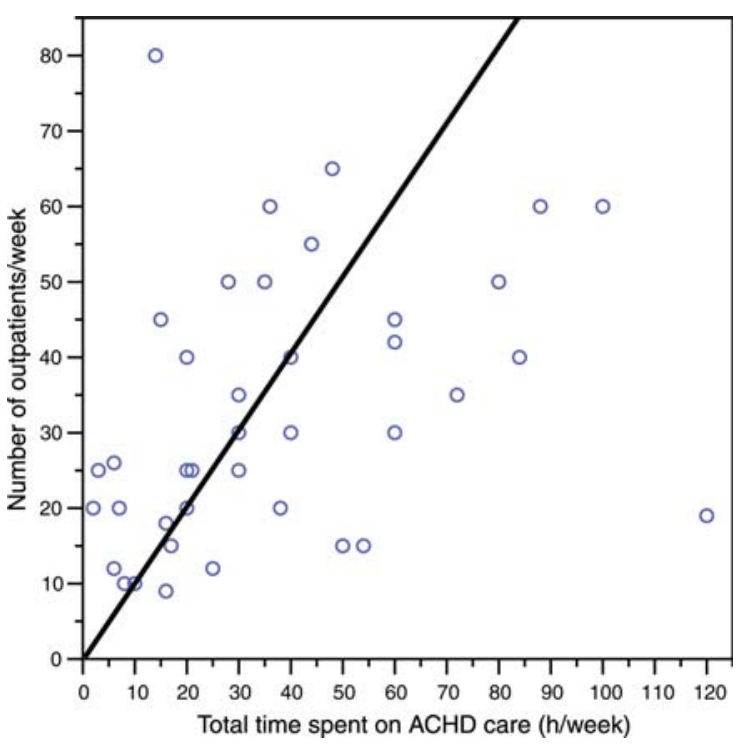

Figure 3 Scatter plot of time spent on adult congenital heart disease care by adult congenital heart disease cardiologists vs. the number of outpatients per week.

Figure 3 shows a scatter plot of the time spent by ACHD cardiologists vs. the number of outpatient visits per week. This scatter plot revealed that wide variability is present in the time devoted to ACHD care by ACHD cardiologists. The diagonal line in the plot represents the median proportion of overall time spent on ACHD care vs. the number of outpatient visits per week (1 h/outpatient visit).

\section{Equipment available}

Table 3 lists the centres' equipment, instruments important for the diagnosis and follow-up of congenital heart defects. All centres had 
Table 3 Equipment available in the $\mathbf{5 0}$ adult congenital heart disease programmes

\begin{tabular}{|c|c|}
\hline & $n(\%)$ \\
\hline Cardiac catheterization & $50(100)$ \\
\hline Electrophysiology & $49(98)$ \\
\hline Magnetic resonance imaging & $48(96)$ \\
\hline Computer tomography & $50(100)$ \\
\hline Nuclear cardiology & $46(92)$ \\
\hline
\end{tabular}

cardiac catheterization and computer tomography available. Electrophysiology, magnetic resonance imaging, and nuclear cardiology were present in 98,96 , and $92 \%$ of the centres, respectively (Table 3).

\section{Training in adult congenital heart disease}

Thirty-four per cent of the ACHD programmes had formally trained fellows in ACHD, with each centre training a median of 2.5 fellows (Table 4). Training for adult cardiologists, paediatric cardiologists, or residents was often provided, either on a regular or rotating basis. Training for medical students and visiting physicians was elective (Table 4).

\section{Supportive services available}

Table 5 lists the auxiliary services available at the centres. All but one centre had cardiac anaesthesia present. Most centres also provided care with respect to obstetrics, contraception, genetics, cardiac rehabilitation, and psychosocial counselling and social work. Heart transplantation and lung transplantation were less frequently available. If a particular service was not available in a centre, patients were referred to other hospitals.

\section{Discussion}

The significant growth in the number of ACHD patients has multiplied the number of ACHD programmes established in Europe. Although the first programmes were established four decades ago, in the majority of centres, dedicated ACHD programmes were founded only in the 1990s. In the present study, we surveyed the structural elements and activities of ACHD programmes in Europe.

We found that existing ACHD programmes had a median of 1500 patients in active follow-up and a median of 800 outpatient visits per year. A broad range in clinical activity was observed, however, confirming the heterogeneity of caseloads in ACHD programmes. Heterogeneity was also found in the time spent on ACHD care per week. The time spent on ACHD care did not correlate well with the number of outpatients per week. Indeed, our survey revealed that in some centres, cardiologists spent a relatively limited time on ACHD care as a function of outpatient caseload. We also found, however, that in some cases, cardiologists spent a lot of time on ACHD care, even though they saw a limited number of patients at the outpatient clinic per week. The median time spent per patient (diagonal line in Figure 3) was $1 \mathrm{~h}$. This figure might help individual centres to benchmark and to
Table 4 Training provided by the $\mathbf{5 0}$ adult congenital heart disease programmes

n (\%)

Has your institution ever formally trained fellows in ACHD?

Yes

If yes, the number of fellows trained to date?

$2.5(2-7.75)^{\mathrm{a}}$

Does your ACHD programme provide training for adult cardiologists/ internal medicine doctors?

Yes

Rotating system

$25(50)$

Elective

No

Unknown

Does your ACHD programme provide training for paediatric cardiologists?

Yes

Rotating system

$15(30)$

Elective

2 (4)

No

16 (32)

Unknown

$3(6)$

Does your ACHD programme provide training for residents?
Yes
$30(60)$
Rotating system
4 (8)
Elective
1 (2)
No
13 (26)
Unknown
$2(4)$

Does your ACHD programme provide training for medical students? Yes

Rotating system

2 (4)

Elective

$18(36)$

No

13 (26)

Unknown

1 (2)

Does your ACHD programme provide training for visiting physicians?

Yes

$13(26)$

Rotating system

$0(0)$

Elective

$25(50)$

No

Unknown

$3(6)$

Median (Q1-Q3).

optimize efficiency or balance workload, if needed. Furthermore, it can be used in manpower planning, because the estimated number of outpatient visits per year can be used to estimate the overall number of man hours per year for ACHD care.

Seventy-one per cent of the centres in Europe were included in this survey. Altogether, these centres have $\sim 100000$ patients in active follow-up. Extrapolating from this figure, we estimate that there are about 130000 patients in follow-up in all European ACHD programmes. This number is alarmingly low. On the basis of extrapolations by Marelli et al., ${ }^{9}$ we can estimate that there are about 3.2 adult patients per 1000 inhabitants. For a population of 
Table 5 Supportive services available in the $\mathbf{5 0}$ adult congenital heart disease programmes

\begin{tabular}{lr}
\hline & $\mathbf{n}(\%)$ \\
Obstetrics & $42(84)$ \\
Contraceptive services & $41(82)$ \\
Cardiac anaesthesia & $49(98)$ \\
Heart transplantation & $29(58)$ \\
Lung transplantation & $18(36)$ \\
Genetics & $40(80)$ \\
Cardiac rehabilitation & $39(78)$ \\
Psychosocial counselling/social work & $43(86)$ \\
\hline
\end{tabular}

568 million persons who are living in the countries in which we have identified one or more ACHD centres, the number of adults with congenital heart disease can be estimated to be about 1.8 million. This would mean that only $7.1 \%$ of adult Europeans with congenital heart disease are currently receiving specialized ACHD care.

\section{Comparison with the literature}

To date, only a few surveys on the structure and clinical activities of ACHD programmes have been published. One survey described the organizational setup, workload, and patient characteristics of five major ACHD programmes in North America and one in Europe. ${ }^{11}$ This survey included the six largest ACHD centres identified at that time and used data collected from 1998 to 2001. The results of this survey are therefore not representative of all ACHD programmes in North America or Europe.

A more general survey was conducted in the USA by the Adult Congenital Heart Association (ACHA). ${ }^{12}$ The investigators targeted paediatric cardiology programmes $(n=48)$, ACHD programmes $(n=174)$, university hospitals $(n=125)$, and other major clinics in the USA. Fifty-five centres responded; these had 32460 patients in active follow-up. The ACHA survey revealed that the number of patients followed increases with centre age. ${ }^{12}$ Hence, older programmes follow 4.2-fold more patients than do newer programmes, ${ }^{12}$ which is in line with the observations of our study.

As part of the Euro Heart Survey on ACHD, ${ }^{13,14}$ the delivery of care for adult patients with congenital heart disease in Europe was investigated. ${ }^{10}$ This study specifically addressed the caseload of health-care professionals, the type of professionals involved, and the extent to which the recommendations are followed to provide optimal care. $^{10}$ The number of centres that employed ACHD cardiologists, paediatric cardiologists, and congenital heart surgeons in the Euro Heart Survey was, to a large extent, comparable to the results of the present study. ${ }^{10}$ This is hardly surprising, since many of the 48 specialist centres that participated in the Euro Heart Survey also partook in the present survey. However, in terms of the involvement of nurse specialists, a big difference emerges. In the Euro Heart Survey, $42 \%$ of the specialist centres had nurse specialists on staff. In the present study, $68 \%$ of the centres employed nurse specialists. This increase reflects an ongoing evolution in Europe: an increasing number of $\mathrm{ACHD}$ programmes are recruiting dedicated nurse specialists. By doing so, centres are meeting international recommendations, which state that 'an ACHD referral centre must employ at least one nurse specialist that is trained and educated in the care of ACHD patients.', 1,8,15-17 Furthermore, centres are improving their structure in order to provide optimal care. ${ }^{10}$ Indeed, the role that nurses play in ACHD patient care is expanding; ${ }^{18,19}$ nurses are performing interventions that contribute to better follow-up and fewer complications. ${ }^{20}$ Furthermore, they play an essential role in the implementation of transition programmes, which prepare adolescents with congenital heart disease for the transfer to adult-focused care. ${ }^{21,22}$

Very recently, a survey on care facilities for ACHD patients in Japan was published. ${ }^{23}$ The investigators sent the survey to 1033 training institutions in Japan, obtaining a response rate of $44 \%$. In this survey, they explored outpatient services, in-hospital services, cardiac surgery activities, management of pregnancy in ACHD women, and adherence to guidelines of the Japanese Circulation Society. ${ }^{23}$ However, since this survey explored the provision of care to ACHD patients in both specialist and non-specialist hospitals, the results cannot be compared with ours.

\section{Methodological issues}

On the basis of the existing network of the ESC Working Group on Grown-up Congenital Heart Disease and our communication with individual providers from different countries, we were able to identify 70 ACHD programmes. Fifty-one programmes were included in the analyses, indicating that the results of this survey concern about three-quarters of the European ACHD programmes. The non-participating centres represented both large and small programmes. Therefore, we believe that our sample is representative of all centres in Europe and that the study findings can be generalized. In this respect, the current study expands the findings of the Euro Heart Survey. ${ }^{10}$

In the present study, we included data from centres in Israel, which actually belong to Asia. Since Israel is a member of the ESC, we did not debar this country from the study.

With respect to clinical activities, we requested information on the number of active patients, outpatient visits per week, hours spent to ACHD care per week, admissions per year, and procedures per year. A few centres could give accurate data, whereas the majority of the participating centres provided approximations.

The present study was conducted at the end of 2007 and the start of 2008. The data reported by the participating programmes pertained to data collected in 2006 or 2007. Since ACHD patients constitute a rapidly growing population, the figures of today will probably be different from those of the past 2-3 years.

Some questions were not uniformly interpreted by the respondents. For instance, we did not a priori define the requirements to be considered as an ACHD cardiologist or a nurse specialist. In a few cases, this led to aberrant responses. Because of such outliers, we did not report ranges of values in this article, but limited our report to medians and quartiles. These measures of central tendency and dispersion are less subject to outliers.

In this survey, we investigated the structure of ACHD programmes in Europe, which did not allow us to draw conclusions 
about processes or outcomes of care. In addition, aspects such as grand rounds, clinical seminars, case discussions, and collaborative research programmes are known to contribute to high-quality care. We did, however, not study these issues in the present survey. Future studies should link structural and organizational elements to mortality and morbidity data.

\section{Conclusion}

We investigated the structural elements and activities of ACHD programmes in Europe. We were able to include a representative sample of ACHD programmes. The existing ACHD programmes in Europe are estimated to have only $7.1 \%$ of the afflicted patients in active follow-up. Staffing and available equipment was relatively equal for all European programmes. In terms of clinical activity, training, and supportive services, more variability across the centres was observed. The data of this study can help individual centres to benchmark and to either optimize efficiency or balance workload for ACHD health-care providers. Important avenues for future developments in ACHD are to establish formal training for ACHD cardiologists, to increase the number of $\mathrm{ACHD}$ programmes, to take sufficient nurse specialists on staff to provide psychosocial and transitional care, and to reduce unnecessary variability in time spent on ACHD care. Health-care institutions, universities, professional organizations, and policy makers should take this up to further improve the care for afflicted patients.

\section{Acknowledgement}

The authors gratefully thank the participating centres for taking the time to complete the survey form.

\section{Funding}

This study was not funded by external bodies.

Conflict of interest: none declared.

\section{References}

1. Deanfield J, Thaulow E, Warnes C, Webb G, Kolbel F, Hoffman A, Sorenson K, Kaemmer $H$, Thilen $U$, Bink-Boelkens M, Iserin L, Daliento L, Silove E, Redington A, Vouhe P, Priori S, Alonso MA, Blanc JJ, Budaj A, Cowie M, Deckers J, Fernandez BE, Lekakis J, Lindahl B, Mazzotta G, Morais J, Oto A, Smiseth O, Trappe HJ, Klein W, Blomstrom-Lundqvist C, de Backer G, Hradec J, Mazzotta G, Parkhomenko A, Presbitero P, Torbicki A. Management of grown up congenital heart disease. Eur Heart J 2003;24:1035-1084.

2. Warnes CA, Williams RG, Bashore TM, Child JS, Connolly HM, Dearani JA, Del Nido P, Fasules JW, Graham TP Jr, Hijazi ZM, Hunt SA, King ME, Landzberg MJ, Miner PD, Radford MJ, Walsh EP, Webb GD. ACC/AHA 2008 Guidelines for the Management of Adults with Congenital Heart Disease: a report of the American College of Cardiology/American Heart Association Task Force on Practice Guidelines (writing committee to develop guidelines on the management of adults with congenital heart disease). Circulation 2008;118:e714-e833.

3. Kaemmerer H, Breithardt G. Empfehlungen zur Qualitätsverbesserung der interdisziplinären Versorgung von Erwachsenen mit angeborenen Herzfehlern (EMAH). Clin Res Cardiol 2006;95:76-84.
4. Hess J, Bauer U, de Haan F, Flesch J, Gohlke-Bärwolf C, Hagl S, Hofbeck M, Kaemmerer $H$, Kallfelz HC, Lange PE, Nock H, Schirmer KR, Schmaltz AA, Tebbe U, Weyand M, Breithardt G. Empfehlungen für Erwachsenenund Kinderkardiologen zum Erwerb der Zusatz-Qualifikation 'Erwachsene mit angeborenen Herzfehlern' (EMAH). Clin Res Cardiol 2007;96:19-26.

5. Wren C, O'Sullivan JJ. Survival with congenital heart disease and need for follow up in adult life. Heart 2001;85:438-443.

6. British Cardiac Society Working Party. Grown-up congenital heart (GUCH) disease: current needs and provision of service for adolescents and adults with congenital heart disease in the UK. Heart 2002;88(Suppl. 1):i1-i14.

7. Gurvitz MZ, Chang RK, Ramos FJ, Allada V, Child JS, Klitzner TS. Variations in adult congenital heart disease training in adult and pediatric cardiology fellowship programs. J Am Coll Cardiol 2005;46:893-898.

8. Landzberg MJ, Murphy DJ Jr, Davidson WR Jr, Jarcho JA, Krumholz HM, Mayer JE Jr, Mee RB, Sahn DJ, Van Hare GF, Webb GD, Williams RG. Task force 4: organization of delivery systems for adults with congenital heart disease. J Am Coll Cardiol 2001;37:1187-1193.

9. Marelli AJ, Therrien J, Mackie AS, lonescu-Ittu R, Pilote L. Planning the specialized care of adult congenital heart disease patients: from numbers to guidelines; an epidemiologic approach. Am Heart J 2009;157:1-8.

10. Moons P, Engelfriet P, Kaemmerer H, Meijboom FJ, Oechslin E, Mulder BJ. Delivery of care for adult patients with congenital heart disease in Europe: results from the Euro Heart Survey. Eur Heart J 2006;27:1324-1330.

11. Niwa K, Perloff JK, Webb GD, Murphy D, Liberthson R, Warnes CA, Gatzoulis MA. Survey of specialized tertiary care facilities for adults with congenital heart disease. Int J Cardiol 2004;96:211-216.

12. Davidson WR Jr, Warren GH, Verstappen A, Kuehl KS, Graham TP. US resources for care of adults with congenital heart disease. Circulation 2006;114(Suppl. 18): II-681.

13. Engelfriet P, Boersma E, Oechslin E, Tijssen J, Gatzoulis MA, Thilen U, Kaemmerer H, Moons P, Meijboom F, Popelova J, Laforest V, Hirsch R, Daliento L, Thaulow E, Mulder B. The spectrum of adult congenital heart disease in Europe: morbidity and mortality in a 5 year follow-up period: the Euro Heart Survey on adult congenital heart disease. Eur Heart $\int$ 2005;26: 2325-2333.

14. Engelfriet P, Tijssen J, Kaemmerer $H$, Gatzoulis MA, Boersma E, Oechslin E, Thaulow E, Popelova J, Moons P, Meijboom F, Daliento L, Hirsch R, Laforest V, Thilen $U$, Mulder B. Adherence to guidelines in the clinical care for adults with congenital heart disease: the Euro Heart Survey on Adult Congenital Heart Disease. Eur Heart J 2006;27:737-745.

15. Therrien J, Dore A, Gersony W, Iserin L, Liberthson R, Meijboom F, Colman JM, Oechslin E, Taylor D, Perloff J, Somerville J, Webb GD. CCS Consensus Conference 2001 update: recommendations for the management of adults with congenital heart disease. Part I. Can J Cardiol 2001;17:940-959.

16. Fifth report on the provision of services for patients with heart disease. Heart 2002;88(Suppl. 3):iii1-iii56.

17. Report of the Paediatric and Congenital Cardiac Services Review Group. London: Department of Health; 2003. p1-49.

18. Moons P, De Geest S, Budts W. Comprehensive care for adults with congenital heart disease: expanding roles for nurses. Eur J Cardiovasc Nurs 2002;1:23-28.

19. Moons P, Hilderson D, Van Deyk K. Congenital cardiovascular nursing: preparing for the next decade. Cardiol Young 2009;19:106-111.

20. Moons P, Scholte op Reimer W, De Geest S, Fridlund B, Heikkila J, Jaarsma T, Martensson J, Smith K, Stewart S, Stromberg A, Thompson DR. Nurse specialists in adult congenital heart disease: the current status in Europe. Eur J Cardiovasc Nurs 2006;5:60-67.

21. Hilderson D, Saidi AS, Van Deyk K, Verstappen A, Kovacs AH, Fernandes SM, Canobbio MM, Fleck D, Meadows A, Linstead R, Moons P. Attitude toward and current practice of transfer and transition of adolescents with congenital heart disease in the United States of America and Europe. Pediatr Cardiol 2009; 30:786-793.

22. Moons P, Hilderson D, Van Deyk K. Implementation of transition programs can prevent another lost generation of patients with congenital heart disease. Eur J Cardiovasc Nurs 2008;7:259-263.

23. Toyoda T, Tateno S, Kawasoe Y, Shirai T, Shiina Y, Matsuo K, Niwa K. Nationwide survey of care facilities for adults with congenital heart disease in Japan. Circ J 2009;73:1147-1150. 